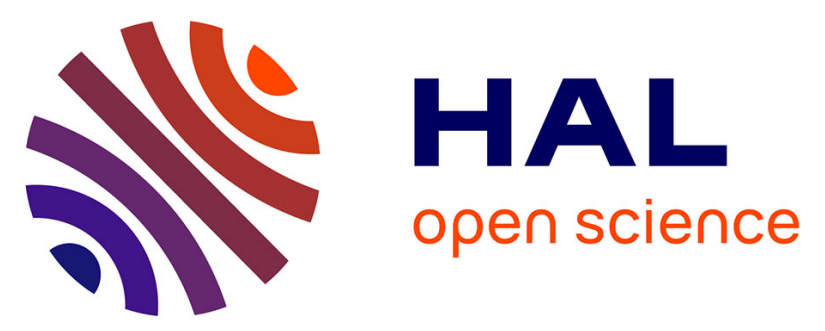

\title{
Three Years of Use of a CSCW Platform by the Preservice Teachers and the Trainers of the Reunion Island Teacher Training School Jean Simon
}

\section{- To cite this version:}

Jean Simon. Three Years of Use of a CSCW Platform by the Preservice Teachers and the Trainers of the Reunion Island Teacher Training School. Ninth IEEE International Conference on Advanced Learning Technologies (ICALT'09), Jul 2009, Riga, Latvia. pp.637-641, 10.1109/ICALT.2009.31 . hal-01188708

\section{HAL Id: hal-01188708 \\ https://hal.univ-reunion.fr/hal-01188708}

Submitted on 24 Feb 2017

HAL is a multi-disciplinary open access archive for the deposit and dissemination of scientific research documents, whether they are published or not. The documents may come from teaching and research institutions in France or abroad, or from public or private research centers.
L'archive ouverte pluridisciplinaire HAL, est destinée au dépôt et à la diffusion de documents scientifiques de niveau recherche, publiés ou non, émanant des établissements d'enseignement et de recherche français ou étrangers, des laboratoires publics ou privés. 


\title{
Three years of use of a CSCW platform by the preservice teachers and the trainers of the Reunion Island teacher training school
}

\author{
SIMON Jean, \\ ERTé CALICO, GRRAPELI, \\ IUFM de La Réunion, \\ Allée des Aigues Marines, \\ 97400 Saint Denis, FRANCE \\ jean.simon@reunion.iufm.fr
}

\begin{abstract}
During three years, teachers trainers and preservice teachers have shared a CSCW platform. In this article we present their work, we see how it was structured, we study its evolution over the three years and, for one year, we classify it in categories. To do so, we use a multimodal analysis based on the higher level shared folder.
\end{abstract}

\section{Introduction}

The Reunion Island teacher training centre/school (IUFM, i.e. University Institute of Teacher Training) prepares trainee primary teachers (PEs, i.e. professeurs des écoles) [11], [12]. Since 2005, trainers and PEs have been using a CSCW platform. PEs wanted a platform to share teaching material. As for them, the trainers had different objectives:

- to improve lesson plans deposited by the trainees

- to allow the trainees to pass the $\mathrm{C} 2 \mathrm{i} 2 \mathrm{e}$, a certificate which confirms their ability to use ICT in education,

- to prepare dissertations,

- to help trainees when they are in charge of a class and have to teach pupils in a primary school with online and at distance advice.

In order to reach these various goals, we chose BSCW because it's an open platform [1] [5][6]. However, this absence of constraint requires users to organize themselves to achieve their objectives [10]. This is this organization we study here so as to characterize the practices [2], to discover the patterns of interactions [9] and the roles played by the various members [7].
In that purpose, we use the higher level shared folders $(h l s f)$ presented quickly in section 2. In Section 3 , we study such folders when they are shared by trainers and PEs and see their evolution over three years. In section 4 , we classify these hlsfs by using a multimodal analysis and see that the organization and the activity generated in these folders depend on the objectives.

\section{Methodology: The Higher Level Shared Folder (hlsf)}

Each year we observe an increase in the number of recordings on BSCW. These recordings are all the traces of activity left on the platform. They correspond to different actions (creation, reading ...) and various objects (files, documents ...). Over the three years, we've been able to study 1516828 traces of this type, left by about 2450 persons. Nevertheless, taken separately, these traces provide little information, this is why we used a tool: the higher level shared folder (hlsf).

The hlsf gathers the different types of traces that can be found on the platform in the same unit of analysis [11], [12]. The hlsf is a folder shared by a group of members. It contains subfolders and different types of documents. This is this unit and the actions which are reported to it that we study. Behind the definition is the idea that the hlsf reflects the activity of the members of a group working together to solve a problem [12]. 


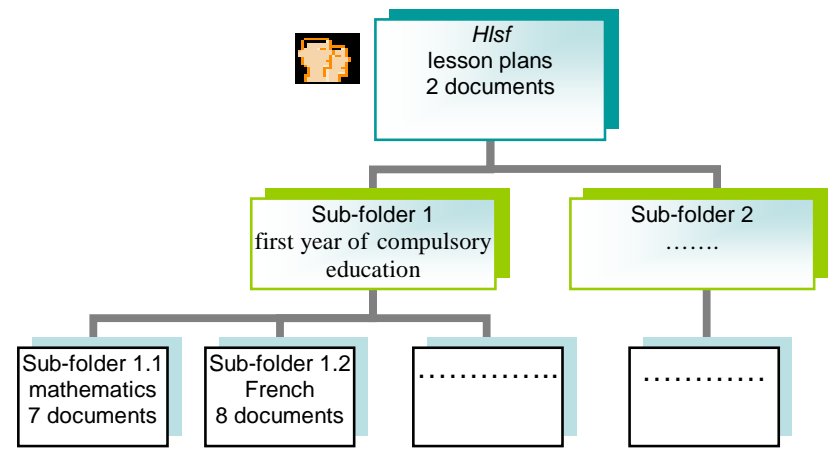

Figure 1. an example of hlsf .

The heads symbolize the members of the group associated with the hlsf. Each folder can contain subfolders and documents $[11,12]$

Thus defined, the hlsf allows us to analyze the activities on the platform according to the groups or according to the objectives they try to achieve:

- In [12] we have presented the hlsfs shared by PEs only. Here, we are interested in the hlsfs shared by PEs and trainers.

- The general objective of all these hlsfs is to enable PEs to manage with a primary class. In section 4 , we see how this objective can be divided into different ways.

\section{Evolution of the $h l s f$ shared by PEs and trainers from 2005 to 2008}

In this section, we show the evolution of the hlsfs shared by PEs and trainers over three academic years.

\subsection{Number of $h l s f s$}

Table 1. Distribution of hlsf over three years

\begin{tabular}{|c|c|c|c|c|}
\hline & $\begin{array}{c}2005- \\
2006\end{array}$ & $\begin{array}{c}2006- \\
2007\end{array}$ & $\begin{array}{c}2007- \\
2008\end{array}$ & $\begin{array}{c}\text { over 3 } \\
\text { years }\end{array}$ \\
\hline nb of hlsf & 78 & 77 & 38 & 193 \\
\hline nb of PEs & 343 & 277 & 217 & 837 \\
\hline nb of hlsf per PE & 0.23 & 0.28 & 0.18 & 0.23 \\
\hline
\end{tabular}

We can notice a decrease of the total number of the $h l s f s$ although it is a relative one: if we relate the number of $h l s f s$ to the number of PEs, we notice a peak in 2006-2007.

\subsection{Size of the groups associated with a hlsf}

Table 2. Distribution of the hlsfs according to the size of

\begin{tabular}{|l|c|c|c|c|}
\hline $\begin{array}{c}\text { \% hlsfs } \\
\text { according to } \\
\text { their size }\end{array}$ & $\begin{array}{c}2005- \\
2006\end{array}$ & $\begin{array}{c}2006- \\
2007\end{array}$ & $\begin{array}{c}2007- \\
2008\end{array}$ & $\begin{array}{c}\text { over 3 } \\
\text { years }\end{array}$ \\
\hline $\begin{array}{l}\text { Less or equal to } \\
13 \text { members }\end{array}$ & $57.69 \%$ & $42.86 \%$ & $39.47 \%$ & $48.19 \%$ \\
\hline $\begin{array}{l}\text { More than 13 } \\
\text { members }\end{array}$ & $42.30 \%$ & $57.14 \%$ & $60.53 \%$ & $51 ; 81 \%$ \\
\hline
\end{tabular}

The Table 2 reveals that the number of members within a group is steadily increasing. The percentage of hlsfs, whose number of members exceeds 13, raises from $42.30 \%$ in $2005-2006$ to $60.53 \%$ in $2007-2008$.

\subsection{Number of documents and sub-folders}

Table 3. distribution of the documents within the folders

\begin{tabular}{|c|c|c|c|c|}
\hline & $\begin{array}{c}2005- \\
2006\end{array}$ & $\begin{array}{c}2006- \\
2007\end{array}$ & $\begin{array}{c}2007- \\
2008\end{array}$ & $\begin{array}{c}\text { over 3 } \\
\text { years }\end{array}$ \\
\hline $\begin{array}{c}\text { A: average number of } \\
\text { documents for one } h l s f\end{array}$ & 17.58 & 33.42 & 73.76 & 34.96 \\
\hline $\begin{array}{c}\text { B: average number of } \\
\text { subfolders for one } h l s f\end{array}$ & 4.52 & 10 & 23.11 & 10.37 \\
\hline ratio : A/(B+1) & 3.18 & 3.04 & 3.06 & 3.08 \\
\hline
\end{tabular}

In Table 3, we see that the average number of documents per hlsf is increasing: it has risen from 17.58 (in 2005-2006) to 73.76 (2007-2008). This can be explained by a capitalization of the documents in the $h l s f s$ by the trainers over the years. Moreover, quite surprisingly, these $h l s f s$ are overorganized and this overorganization carries on over the years: a folder (hlsf or sub-folder) contains an average of 3 documents while it could contain more without losing legibility.

\subsection{Type of participation}

Table 4: numbers and percentages of PEs according to various types of carried out actions

\begin{tabular}{|c|c|c|c|c|c|c|c|c|}
\hline \multirow[t]{2}{*}{$\mathrm{Nb}$ of PEs } & \multicolumn{2}{|c|}{ 2005-2006 } & \multicolumn{2}{|c|}{ 2006-2007 } & \multicolumn{2}{|c|}{ 2007-2008 } & \multicolumn{2}{|c|}{$\begin{array}{c}\text { over } 3 \\
\text { years }\end{array}$} \\
\hline & $\mathrm{nb}$ & $\%$ & $\mathrm{nb}$ & $\%$ & $\mathrm{nb}$ & $\%$ & $\mathrm{nb}$ & $\%$ \\
\hline leader & 10 & $3 \%$ & 14 & $5 \%$ & 4 & $2 \%$ & 28 & $3 \%$ \\
\hline moderator & 61 & $18 \%$ & 98 & $35 \%$ & 80 & $37 \%$ & 239 & $29 \%$ \\
\hline producer & 142 & $41 \%$ & 229 & $83 \%$ & 171 & $79 \%$ & 542 & $65 \%$ \\
\hline reader & 285 & $83 \%$ & 264 & $95 \%$ & 217 & $100 \%$ & 766 & $92 \%$ \\
\hline member & 343 & $100 \%$ & 277 & $100 \%$ & 217 & $100 \%$ & 837 & $100 \%$ \\
\hline
\end{tabular}

In table 4, to analyze the reality of the participation, we focused on the actions carried out in these hlsfs by the PEs and the role they have taken [7]. We distinguished between leader (creator of one hlsf at 
least), moderator (creator of one sub-folder at least), producer (creator of one document at least) and reader.

Since 2006-2007, there have been no significant changes in the assignment of roles within the hlsfs. The trainees are rarely leaders or moderators: it is mainly trainers who create the hlsfs and structure them in subfolders. On the other hand, an average of $80 \%$ of PEs are producers.

\subsection{Conclusion for this section}

Thus, we note that the activity over the three years in the hlsfs shared by trainers and PEs has evolved. The number of $h l s f s$ has decreased but these hslfs have gained in density. There are more documents and larger groups. This increasing number of documents is probably the result of a progressive capitalization by the trainers over the years. We can suppose that with a long-run experience the trainers got used to the practice of the platform and this has modified the way they use it. Nevertheless, the assignment of roles has not changed since 2006 .

\section{Classification of the hlsfs}

\subsection{Criteria used for classification}

We wanted to characterize the hlsfs because they have been created to achieve various objectives (see section 1). This spread in the objectives appears in the dispersal of values compared to the average that can be seen by calculating the standard deviations (for the number of documents for example).

Thus, by using a multimodal analysis (social networks analysis, textual analysis...) of the hlsfs shared by trainers and PEs during the academic year 2006-2007, we have been able to define 6 categories. The dispersion of the values compared to the average raised our attention on two first categories:

- The "empty" hlsfs which contained no document;

- $\quad$ The "FADIR"1 hlsfs who had several hundred of them.

For the following ones, we have used the analysis of the social networks of the groups associated with the $h l s f s$ carried out by [4] which shows that among all the variables associated with a hlsf (number of folders, documents, readers, readings,...) the key variable is the

${ }^{1}$ The word "FADIR" was in the titles. "FADIR" is a French acronym. It means e-learning at the IUFM. number of producers. Therefore, we distinguished between the $h l s f$ where there is only one producer and the others. The fact that there is only one producer indicates that the $h l s f$ is used to disseminate the information rather than to exchange it. This is why, always by basing us on the social networks, we burst this category into two others according to whether the producer is a PE or a trainer.

In the end, to analyze the 30 remaining hlsfs (with several producers) we did a textual analysis of the titles. On the basis of seven terms, we could classify 69 of the 77 titles. One of these terms, the acronym "TICE" ${ }^{2}$, appeared in 20 of them. So, we burst these 30 hlsfs into two categories: "TICE" and "others".

\subsection{The obtained classification}

Table 5. Classification of the hlsfs in 6 categories

("1TP" means "one trainer producer", "1PP" means "one PE Producer", "av.nb" means "average number")

\begin{tabular}{|c|c|c|c|c|c|c|c|}
\hline category & $\begin{array}{c}e m p \\
\text { ty }\end{array}$ & $1 \mathrm{PP}$ & $1 \mathrm{TP}$ & other & TICE & $\begin{array}{c}\text { FAD } \\
\text { IR }\end{array}$ & total \\
\hline nb of hlsf & 7 & 21 & 14 & 13 & 20 & 2 & 77 \\
\hline $\begin{array}{c}\text { depth } \\
\text { av.nb. of } \\
\text { sub-folder }\end{array}$ & 1 & 1 & 2 & 2 & 3 & 7 & 2 \\
\hline $\begin{array}{c}\text { av.nb. of } \\
\text { documents }\end{array}$ & $\mathbf{0}$ & $\mathbf{5}$ & $\mathbf{1 0}$ & $\mathbf{2 8}$ & $\mathbf{3 9}$ & $\mathbf{5 9 1}$ & $\mathbf{3 3}$ \\
\hline $\begin{array}{c}\text { av.nb. of } \\
\text { trainer docu. }\end{array}$ & 0 & 0 & 10 & 12 & 5 & 93 & 8 \\
\hline $\begin{array}{c}\text { av.nb. of PEs } \\
\text { document }\end{array}$ & 0 & 5 & 0 & 16 & 34 & 498 & 26 \\
\hline $\begin{array}{c}\text { av.nb. of } \\
\text { member }\end{array}$ & $\mathbf{1 5}$ & $\mathbf{1 9}$ & $\mathbf{2 4}$ & $\mathbf{2 0}$ & $\mathbf{1 9}$ & $\mathbf{4 2}$ & $\mathbf{2 0}$ \\
\hline $\begin{array}{c}\text { av.nb. of } \\
\text { trainer }\end{array}$ & 1 & 1 & 1 & 1 & 1 & 9 & 1 \\
\hline $\begin{array}{c}\text { av.nb. of } \\
\text { PEs }\end{array}$ & 14 & 18 & 23 & 19 & 18 & 34 & 19 \\
\hline $\begin{array}{c}\text { av.nb. of } \\
\text { producers }\end{array}$ & $\mathbf{0}$ & $\mathbf{1}$ & $\mathbf{1}$ & $\mathbf{7}$ & $\mathbf{1 4}$ & $\mathbf{4 1}$ & $\mathbf{6}$ \\
\hline $\begin{array}{c}\text { av.nb. of } \\
\text { trainers } \\
\text { producers }\end{array}$ & 0 & 0 & 1 & 1 & 1 & 8 & 1 \\
\hline $\begin{array}{c}\text { av.nb. of PEs } \\
\text { producers }\end{array}$ & 0 & 1 & 0 & 6 & 13 & 33 & 5 \\
\hline $\begin{array}{c}\text { av.nb. of } \\
\text { readings }\end{array}$ & $\mathbf{0}$ & $\mathbf{2 7}$ & $\mathbf{1 0 4}$ & $\mathbf{1 2 4}$ & $\mathbf{1 5 4}$ & $\mathbf{2 5 0 3}$ & $\mathbf{1 5 3}$ \\
\hline $\begin{array}{c}\text { av.nb. of } \\
\text { trainers } \\
\text { readers }\end{array}$ & 0 & 1 & 1 & 1 & 1 & 9 & 1 \\
\hline $\begin{array}{c}\text { av.nb. of } \\
\text { trainers' } \\
\text { readings }\end{array}$ & 0 & 2 & 8 & 10 & 26 & 620 & 27 \\
\hline $\begin{array}{c}\text { av.nb. of PEs } \\
\text { readers }\end{array}$ & 0 & 8 & 18 & 16 & 19 & 41 & 14 \\
\hline $\begin{array}{c}\text { av.nb. of PEs } \\
\text { readings }\end{array}$ & 0 & 25 & 96 & 114 & 128 & 1884 & 123 \\
\hline
\end{tabular}

\footnotetext{
2 "TICE" means "ICT for Education"
} 
These categories correspond with the majority of the objectives the trainers had assigned to the work on the platform.

Two of these six categories (TICE and FADIR) were known a priori.

The 20 hlsfs TICE aimed at having the PEs take the C2i2e. This certificate, as the French Ministry of Education claims, is attesting that the preservice teacher is able to use the ICT with the pupils.

The 2 hlsfs FADIR aimed at helping trainees when they were in charge of a class through answers "just in time" and "just enough" to their questions. The adopted protocol was rather complex and implied a lot of exchanges on the platform [13].

The category "empty" includes $7 \mathrm{hlsf}$ that have been created but not used thereafter, probably because they did not meet a real need.

The 14 hlsfs "one trainer producer" (1TP) have been used to put online courses or reference documents. The titles refer to the discipline (5) and/or the level (2) and/or the group of trainees (8).

The category of the 21 hlsfs "one producer PE" (1PP) corresponds to the online setting of lessons plans or teaching sequences. The titles of the hlsfs are essentially the producer's name (6) and / or the type of lesson or sequence (12) and / or the name of the discipline (7).

The category "others", as its name suggests, contains the 13 hlsfs not belonging to any of the preceding categories. The analysis of the titles gives a result very close to the category "1TP": discipline (9) and/or level (3) and/or group of trainees (10).

The Table 5 indicates the number of $h l s f s$ for these various categories, but also how it was structured ( number of sub-folders and depth, number of levels of sub-folders) and who (number of trainers or PEs) did what (number of documents deposited or number of readings).

We ordered the categories in the table according to the number of documents deposited. Thus, we can notice that all the other variables depend on this number of documents except for the variable "number of members".

We observe that the category "FADIR" is actually quite different from the others on all variables. Although comprising only twice more members than the average of the other hlsfs, it has a number of documents deposited (eighteen times more) and a number of readings (sixteen times more) much higher than the average. Moreover they are the only hlsfs in which several trainers took part.
These differences can be explained by the objective of these $h l s f$ which was to accompany PEs when they were in charge of a class. As a consequence, PEs had to deposit various documents before, during and after the training course. On their side, the trainers had to make comments on these productions and, in their turn, to deposit documents to answer the trainee's questions. That's why these hlsfs were extremely active.

The differences are much lower among the other categories, still we can make a few observations.

As one can expect, the organization (number of subfolders and depth) depends on the number of documents. The more documents there are, the more necessary it is to organize them into folders and subfolders. Nevertheless, we can say that the overorganization (number of documents related to the number of folders) announced in the 3.3 is true for each category of hlsf.

There is also an effect of "institutional pressure": the more the institution takes part in the hlsf, the more active the PEs are. The institution is more involved when, for example, the trainers are the creators of the $h l s f$ or when the hlsf, as TICE, is designed to validate the trainee.

In the hlsfs with only one producer, when this producer is a trainer there are more documents deposited (twice more) and even more readings (almost four times more) than when this producer is a PE. However, this pressure has some limits: in the hlsfs proposed by one trainer, we can point out that all PEs do not read every document: on average only 18 PEs readers out of 23 PEs members share only 103 readings out of 230 possible readings $(23 \times 10)$.

This effect of "institutional pressure" also occurs with the hlsfs TICE in which PEs are required to deposit documents if they want to pass the C2i2e. Thus, if we compare them with the hlsf "others", the hlsfs "TICE" gather on average 39 documents, of which 34 are deposited by PEs, whereas in the hlsf "others", there are only 28 documents, including 16 deposited by PEs.

\subsection{Conclusion for this section}

We showed that the organization and the activity within a $h l s f$ are function of the objectives that this hlsf aims at. Between a hlsf created by a trainer only to present his documents to his trainees (1TP) and another intended to accompany a group of PEs in a training course (FADIR), there is a huge difference in terms of quantity but also in terms of quality. Whereas, in the first case, there is only information broadcasting from the trainer towards the trainees, in the other, there are a 
lot of exchanges of information between trainers and trainees. The first case belongs to the framework of traditional pedagogy whereas the second belongs to the framework of socio-constructivism.

\section{General conclusion}

As far as the methodology is concerned, the clustering of the traces within the hlsfs to use them as the units of analysis is relevant. Grouping the traces within the hlsf made it possible to obtain more information than what we would have obtained by a simple counting of the traces taken separately.

A multimodal analysis of these hlsf (social networks, textual...) allows us to be even more precise [8]. It is important to note that this multimodal analysis mixes the analyses rather than it juxtaposes them. For example, it is the study of the social networks of the groups associated with the $h l s f$, and not the one of the groups in general which enabled us to focus on the number of producers by $h l s f$.

As far as the results are concerned, the analysis over three years shows that the activity on the platform has evolved: less hslfs shared by trainers and trainees but these contain more documents (effect of a probable capitalization from one year to the other). The hslfs remain overorganized and the associated groups are larger. Thus, the hlsfs have evolved to be scarcer and in the same time denser. A question arises: did it allow them to be more effective?

The multimodal categorization of the hlsfs of 2006/07 shows that the trainers have set up the activities they had planned and, that, according to the objectives, the hslfs have taken different forms: ranging from the broadcasting of information within the framework of a classical pedagogy to a collaborative work within the framework of socioconstructivism.

\section{References}

[1]Bentley R., Appelt W., Busbach U., Hinrichs E., Kerr D., Sikkel K., Trevor J., Woetzel G. "Basic Support for Cooperative Work on the World Wide Web.", International Journal of Human Computer Studies: Special issue on Novel Applications of the WWW, Spring 1997, Academic Press, Cambridge, vol. 46, nº, 1997, p. 827-846.

[2]Carroll J.M.., Choo C W , Dunlap D R., Isenhour Pl, Kerr St,Maclean A, Rosson Mb (2003) "Knowledge Management Support for Teachers", ETR\&D, Vol. 51, № 4, 2003, pp.4264

[4]Gerard J-P, "Analyse des réseaux sociaux associées aux dossiers partagés par des professeurs des écoles stagiaires", accepted by Tematice, Milan, 2009
[5]González V.R., García De La Santa A., Gorghiu G., Gorghiu L.M. "BSCW as a support system for distance teacher training.", Recent Research Developments in Learning Technologies, Proceedings of the Third International Conference on Multimedia \& ICT's in Education, vol. 2, 2005, p. 696-701.

[6]Hakkinen P., Jarvela S., Makitalo K. "Sharing perspective in virtual interaction.", B. Wasson, S. Ludvigen, U. hoppe (Eds) Computer Support for Collaborative Learning: Designing for change in Networked Environments. Proceedings of CSCL 2003, Dordrecht: Kluwer Academic Publishers, 2003, p. 395-404.

[7]Herrmann T., Jahnke I., Loser K.U. "The Role Concept as a Basis for Designing Community Systems.", Cooperative Systems Design, Scenario-Based Design of Collaborative Systems, F. Darses, R. Dieng, C. Simone \& M. Zacklad (Eds.), 2004, p. 163-178.

[8]Martinez A., Dimitriadis Y., Gomez E., Jorrin I., Rubia B., Marcos J.A. "Studying participation networks in collaboration using mixed methods.", International Journal of Computer-Supported Collaborative Learning, Springer New York. Vol. 1, n³, September, 2006, p. 383-408.

[9]Schlager M, Fusco J. "Teacher Professional Development, Technology, and Communities of Practice: Are We Putting the Cart Before the Horse?" The Information Society, Volume 19, Number 3, Jul-Aug 2003 , pp. 203-220(18)

[10] Sikkel K., Gommer L., Van Der Veen J. "Using Shared Workspaces in Higher Education.", Innovations in Education and Teaching International, Vol. 39, $\mathrm{n}^{\circ} 1$, January 01, 2002, p. 26-45.

[11]Simon J, Gerard J-P, Thevenin C., "Dossiers partagés par les stagiaires avec ou sans formateur à l'IUFM de La Réunion: Analyses des traces." In STICEF Volume 15, 2008, Numéro spécial EPAL, Grenoble, 2007

[12] Simon J, "Three years of teaching resource sharing by primary school teachers trainees on a CSCW" platform, accepted by CSCL, Rhodes, 2009

[13] Thevenin, C., Gerard J-P, Simon J. "Le juste à temps et le juste ce qu'il faut comme dynamiques de soutien à un accompagnement de stage professionnel scénarisé. Analyse d'une expérience." JOurnées Communication et Apprentissage Instrumentés en Réseau (JOCAIR'06), Amiens, France. 2006, p. 483-500. 